\title{
sciendo
}

\section{FIBER DIGESTIBILITY IN GROWING PIGS FED COMMON FIBER-RICH INGREDIENTS - A SYSTEMATIC REVIEW}

\author{
Pan Yang, Jinbiao Zhao* \\ State Key Laboratory of Animal Nutrition, College of Animal Science and Technology, China Agricultural University, Beijing 100193, China \\ •Corresponding author: jinbiaozhao@cau.edu.cn
}

\begin{abstract}
The application of high-fiber ingredients in the swine feed industry has some limitations considering that high amounts of fiber are resistant to endogenous enzymatic degradation in the pig's gut. However, there is growing interest in fiber fermentation in the intestine of pigs due to their functional properties and potential health benefits. Many strategies have been applied in feed formulations to improve utilization efficiency of fiber-rich ingredients and stimulate their prebiotic effects in pigs. This manuscript reviews chemical compositions, physical properties, and digestibility of fiber-rich diets formulated with fibrous ingredients for growing pigs. Evidences presented in this review indicate there is a great variation in chemical compositions and physical properties of fibrous ingredients, resulting in the discrepancy of energy and fiber digestibility in pig intestine. In practice, fermentation capacity of fiber components in the pig's intestine can be improved using strategies, such as biological enzymes supplementation and feed processing technologies. Soluble dietary fiber (SDF) and insoluble dietary fiber (IDF), rather than neutral detergent fiber (NDF) and acid detergent fiber (ADF), are recommended in application of pig production to achieve precise feeding. Limitations of current scientific research on determining fiber digestibility and short chain fatty acids (SCFA) production are discussed. Endogenous losses of fiber components from non-dietary materials that result in underestimation of fiber digestibility and SCFA production are discussed in this review. Overall, the purpose of our review is to provide a reference for feeding the pig by choosing the diets formulated with different high-fiber ingredients.
\end{abstract}

Key words: digestibility, fiber fermentation, microbiota, pig, short chain fatty acid

Dietary fiber is a series of complex compounds which cannot be digested by digestive enzymes secreted by animals, but can be partly or completely fermented by gut microbiota to produce short chain fatty acids (SCFA) in the intestine (Williams et al., 2001). Traditionally, dietary fiber intake reduces energy and nutrient digestibility, and ultimately decreases growth performance of pigs (Dégen et al., 2009). To mitigate the negative effects of dietary fiber, many studies have focused on approaches to improve utilization efficiency of dietary fiber in pigs, such as supplementation of enzymes and feed processing technologies (Zijlstra et al., 2010; Molist et al., 2010). In addition, some recent studies have reported that dietary fiber and its fermentation metabolites can maintain physiological status and benefit the immune function and health of pigs (Molist et al., 2014; Zhao et al., 2018 a). The SCFA produced by dietary fiber fermentation mainly includes acetate, propionate, and butyrate, which play an important role in regulating metabolism, immunological function, and gut cell proliferation of the host (Koh et al., 2016). Butyrate is an energy source for colonocytes to maintain gut barrier functions, whereas acetate and pro- pionate are delivered to peripheral circulation through the portal vein to participate in metabolic activities of the liver and peripheral tissues (Liu et al., 2018). In addition, there is great variation in nutrient digestibility, fermentation capacity, and SCFA production among various fiberrich ingredients because of their diverse physicochemical characteristics (Urriola and Stein, 2010; Bach Knudsen et al., 2013; Jaworski and Stein, 2017). To better understand the role of dietary fiber in pigs and to promote utilization of dietary fiber in pig production, this paper reviews digestibility of fibrous components in diets formulated with common fiber-rich ingredients, and summarizes factors affecting fermentation capacity of dietary fiber components.

\section{Chemical components of dietary fiber}

In general, dietary fiber is derived mainly from the cell walls of plants (Figure 1). Plant cell walls are a mixture of polysaccharides, phytate, protein, and phenol complexes, among which polysaccharides (e.g. cellulose, hemicellulose, pectin, and gums) are the major components of dietary fiber. According to solubility in water, 
dietary fiber can be classified into two categories: soluble dietary fiber (SDF) and insoluble dietary fiber (IDF). The SDF is composed of pectin, $\beta$-glucan, gums, and soluble hemicellulose, and IDF is composed of cellulose, lignin, and insoluble hemicellulose (Williams et al., 2019). Alternatively, dietary fiber can be classified into neutral detergent fiber (NDF) and acid detergent fiber (ADF), which are commonly used in pig nutrition due to high cost of SDF and IDF analysis. However, NDF and ADF primarily contain cellulose, lignin, and insoluble hemicellulose, but soluble fiber components are not measured. The main physical characteristics of dietary fiber include water holding capacity, viscosity, swelling, and fermentability (Bach Knudsen et al., 2001). Water holding capacity is the ability of dietary fiber to form a colloidal suspension in water, which depends on the types of glycosidic bonds and compositions of polysaccharides present (Kelkar et al., 2012). Viscosity of dietary fiber can directly affect physiological function of the gastrointestinal tract of pigs. Viscosity of soluble fiber fractions is usually higher than that of insoluble fiber fractions (Dikeman and Fahey, 2006). In addition, dietary fibers containing longchain polysaccharides are easier to form a net structure than those with short-chain fractions, resulting in greater viscosity. Swelling occurs when fiber solubilizes, which is dependent on water binding capacity of fiber fractions (Bach Knudsen et al., 2013). Fermentation relies on the expansion and dispersion of fiber components, which allows microbial enzymes to have more rapid and complete access to dietary fiber. Generally, varying physical characteristics of fiber among fiber-rich ingredients are associated with fiber composition and are related to the molecule structure of plant cell walls. the cecum and proximal colon of pigs, while IDF residues are fermented primarily in the distal colon (Jaworski and Stein, 2017). Some SDF fractions can also be fermented in the small intestine of pigs (Sholly et al., 2011; Lærke et al., 2015), because fiber-degrading bacteria are found in the stomach and small intestine (Zhao et al., 2019 a). Digestibility of dietary fiber fractions in the distal ileum of pigs ranged from $-7 \%$ to $40 \%$ (Bach Knudsen et al., 2013), which illustrates that large variation exists in fiber digestibility along the small intestine of pigs. Compared to xylose and arabinose, $\beta$-glucan is highly fermentable in the small intestine because of its soluble characteristics (Jha et al., 2010, 2011). Interestingly, existence of negative values for fiber digestibility suggests that there is endogenous loss of fiber components in the pig's intestine (Bach Knudsen et al., 2013), which can largely affect determination of fiber digestibility and SCFA production derived from dietary fiber. There is a large variation in fermentability of dietary fiber in the hindgut of pigs, which ranged from $48 \%$ to $95 \%$ (Jha et al., 2010; Jha and Leterme, 2012). Pectin and soluble hemicellulose are more easily fermented than cellulose, and $\beta$-glucan is almost completely fermented in the hindgut of pigs (Jha et al., 2010).

The primary microbial metabolites produced from fiber fermentation are lactate and SCFA. Lactate is produced mainly in the stomach and small intestine, while SCFAs, especially butyrate, are produced from fiber fermentation in the cecum and colon of pigs (Zhao et al., 2019 a). Nielsen et al. (2014) reported that resistant starch and arabinoxylan supplied by wheat and rye could stimulate butyrate-producing microorganisms, leading to enhanced butyrate production, whereas fermentation of

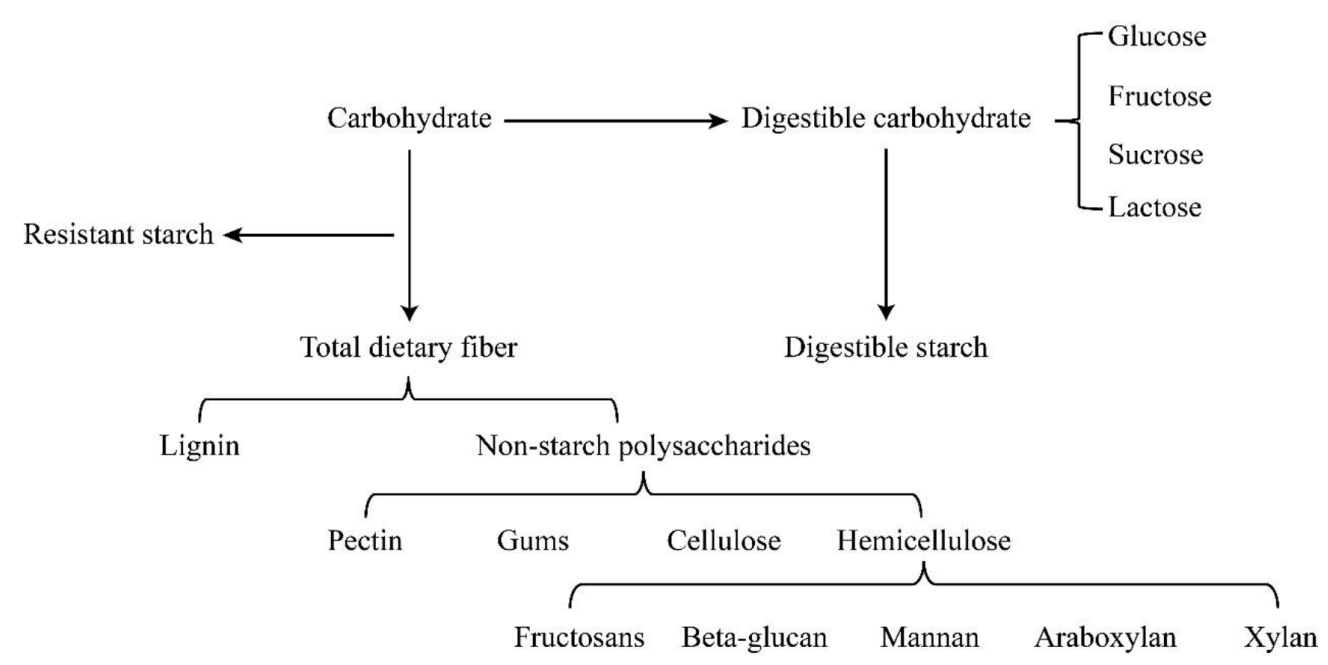

Figure 1. Classification of dietary fiber components in feed ingredients (Adapted from Bach Knudsen et al., 2013)

Dietary fiber fermentation in the intestine of pigs

Apparent total tract digestibility (ATTD) of SDF was reported to be $20 \%$ greater than that of IDF, indicating that SDF is more fermentable by gut microbiota than IDF in the intestine of pigs (Urriola et al., 2010). Most SDF fractions with high fermentability are degraded mainly in cellulose derived from wheat increased acetate concentration. Therefore, dietary fiber source can greatly affect the fermentability of dietary fiber and the amount or type of SCFA produced in the pig intestine. In addition, our previous study showed that total SCFA concentration in ileal digesta was correlated positively with apparent il- 
eal digestibility (AID) of cellulose and concentration of acetate was correlated positively with ATTD of IDF in fecal samples. A regression equation to predict fecal acetate concentration using a combination of ADF and SDF digestibility $\left(R^{2}=0.85 ; P=0.06\right)$ was better than similar equations using ATTD of $\mathrm{ADF}\left(R^{2}=0.55 ; P=0.09\right)$ or IDF $\left(R^{2}=0.72 ; P=0.03\right)$ (Zhao et al., 2019 a). Regression equations for fecal butyrate $\left(R^{2}=0.65 ; P=0.05\right)$ and total SCFA concentrations $\left(R^{2}=0.61 ; P=0.07\right)$ were developed using ATTD of IDF (Zhao et al., 2019 a). However, more animal trials to determine fiber digestibility and SCFA concentrations must be conducted to improve accuracy and precision of prediction equations for SCFA concentrations.

Energy and fiber digestibility in diets containing common fiber-rich ingredients

Fiber-rich ingredients in feed can be categorized according to the amount and proportions of IDF or SDF fractions. Insoluble fiber sources commonly used in pig diets are hulls and brans from cereals and legumes, with representative ingredients including alfalfa meal (Zhao et al., 2018 b), oat hulls (Ndou et al., 2019), corn by-products (Li et al., 2018; Wang et al., 2019), and wheat by-products (Zhao et al., 2018 c; Casas et al., 2018). On the other hand, the most commonly-used ingredients that supply soluble fiber to pig's diets are sugar beet pulp (Zhang et al., 2013), oat bran (Lyu et al., 2018 b), and konjac flour (Li et al., 2018). Soybean hulls have both high amount of insoluble fiber and soluble fiber fractions (Jaworski and Stein, 2017). Chemical composition of fiber-rich ingredients commonly used in pig diets are summarized and presented in Table 1. Different processing technologies for a same fiber-rich ingredient would affect its fermentability of fiber. For example, the SDF proportion in sugar beet pulp ranged from $5 \%$ to $27.5 \%$ according to some previous reports (Zhao et al., 2020 a; Wang et al., 2019; Urriola and Stein, 2012; Navarro et al., 2018 a).

Table 1. Chemical composition of fibrous ingredients commonly used in diets of growing pigs (\%, as-fed basis)

\begin{tabular}{|c|c|c|c|c|c|c|c|c|c|c|}
\hline Item & GE & $\mathrm{CP}$ & $\mathrm{DM}$ & $\mathrm{EE}$ & Ash & NDF & $\mathrm{ADF}$ & $\mathrm{TDF}$ & SDF & IDF \\
\hline Alfalfa meal & 16.2 & 16.1 & 93.3 & 3.2 & 10.6 & 46.2 & 29.3 & 65.8 & 13.2 & 52.6 \\
\hline Canola meal & 17.9 & 40.5 & 88.9 & 4.1 & 7.1 & 23.6 & 17.3 & 26.4 & 1.0 & 25.4 \\
\hline Copra expeller & 19.7 & 21.7 & 96.5 & 11.2 & 5.6 & 48.1 & 23.8 & 43.8 & 1.8 & 42.1 \\
\hline Corn bran & 15.9 & 14.8 & 92.0 & 3.9 & 2.5 & 52.0 & 16.2 & 54.1 & 5.9 & 48.2 \\
\hline Corn germ meal & 17.8 & 19.9 & 92.3 & 1.9 & 1.7 & 46.4 & 13.3 & 49.3 & 2.8 & 46.5 \\
\hline Corn gluten feed & 17.0 & 21.0 & 91.3 & 2.1 & 5.2 & 38.6 & 11.6 & 40.3 & 2.1 & 28.2 \\
\hline Corn DDGS & 18.9 & 26.5 & 85.2 & 8.8 & 5.1 & 37.0 & 17.8 & 38.7 & 1.7 & 37.0 \\
\hline Flaxseed meal & 19.5 & 33.9 & 93.6 & 7.8 & 6.9 & 41.6 & 14.7 & 30.2 & - & - \\
\hline Konjac flour residues & 15.3 & 18.6 & 89.7 & 1.0 & 8.1 & 30.2 & 8.2 & 27.8 & 13.3 & 14.5 \\
\hline Oat bran & 17.2 & 20.6 & 93.0 & 7.5 & 5.3 & 39.1 & 8.8 & 46.0 & 18.2 & 27.8 \\
\hline Oat hulls & 17.2 & 2.5 & 92.3 & 1.7 & 4.8 & 73.5 & 39.8 & 55.8 & 3.9 & 51.9 \\
\hline Palm kernel expeller & 17.9 & 15.6 & 90.0 & 5.8 & 5.2 & 50.9 & 24.6 & 46.6 & 0.6 & 46.0 \\
\hline Rapeseed meal & 17.6 & 36.2 & 88.9 & 3.9 & 6.9 & 30.1 & 19.3 & 26.4 & 4.4 & 22.0 \\
\hline Rapeseed expeller & 17.5 & 35.6 & 91.8 & 11.5 & 6.2 & 24.9 & 17.9 & - & - & - \\
\hline Rice bran (full-fat) & 19.6 & 14.2 & 90.1 & 17.1 & 7.9 & 19.9 & 8.6 & 26.5 & 4.4 & 22.1 \\
\hline Rice bran (defatted) & 15.7 & 15.2 & 91.2 & 1.0 & 10.5 & 30.5 & 18.9 & 35.6 & 1.4 & 34.2 \\
\hline Rice hulls & 18.3 & 8.5 & 91.4 & 7.2 & 4.9 & 57.7 & 31.5 & 68.4 & 5.5 & 62.9 \\
\hline Soybean hulls & 14.7 & 17.4 & 91.3 & 2.9 & 7.2 & 53.2 & 30.2 & 63.1 & 11.2 & 51.9 \\
\hline Sugar beet pulp & 14.1 & 9.7 & 86.9 & 0.4 & 2.5 & 57.7 & 21.2 & 69.8 & 27.4 & 42.5 \\
\hline Sunflower meal & 17.1 & 30.8 & 89.3 & 1.7 & 7.6 & 38.8 & 25.9 & 45.1 & 4.8 & 40.3 \\
\hline Wheat bran & 16.9 & 17.5 & 88.3 & 2.8 & 5.1 & 37.9 & 11.1 & 42.4 & 4.1 & 38.3 \\
\hline Wheat middlings & 16.9 & 17.2 & 87.4 & 3.8 & 4.8 & 33.2 & 9.8 & 37.1 & 2.6 & 34.5 \\
\hline
\end{tabular}

The data were collected from our lab; Corn DDGS, corn distiller's dried grains with solubles; GE, gross energy; CP, crude protein; DM, dry matter; EE, ether extract; NDF, neutral detergent fiber; ADF, acid detergent fiber; TDF, total dietary fiber; SDF, soluble dietary fiber; IDF, insoluble dietary fiber. 


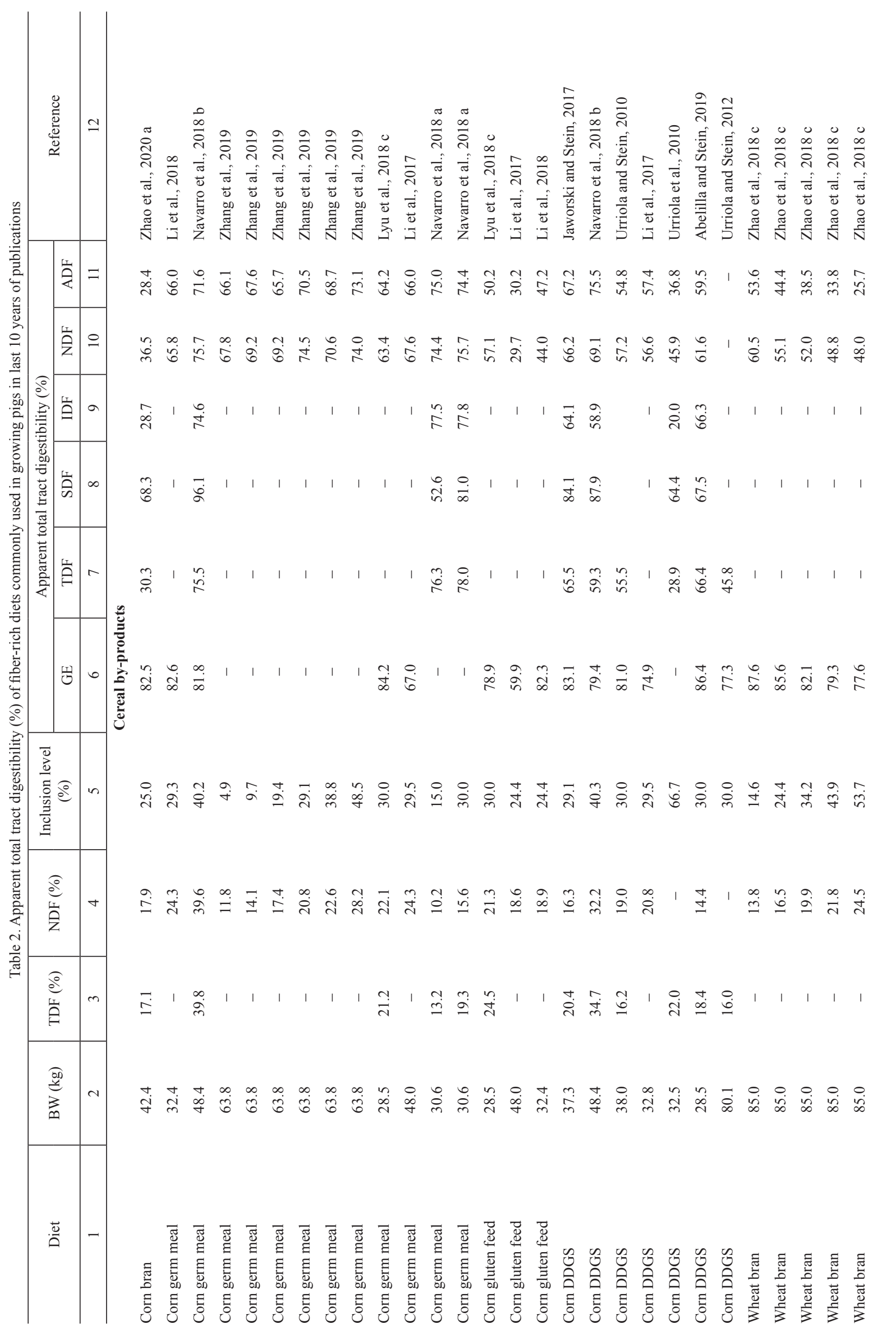




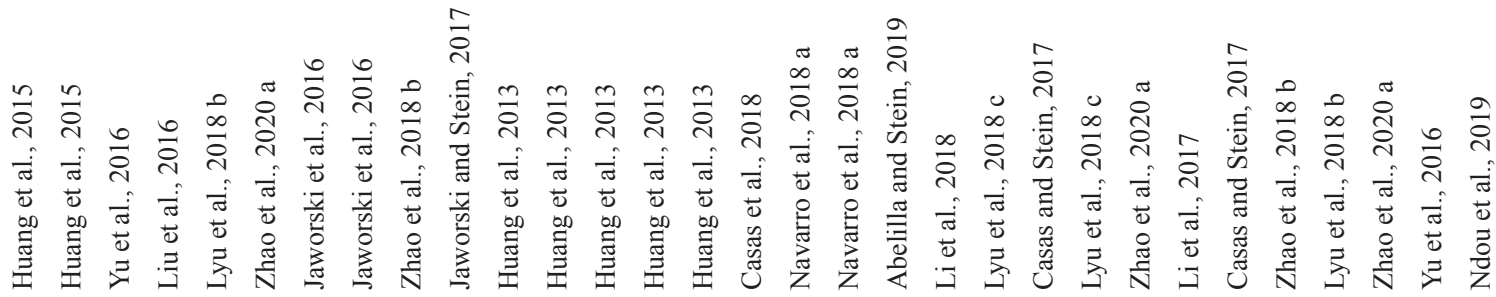

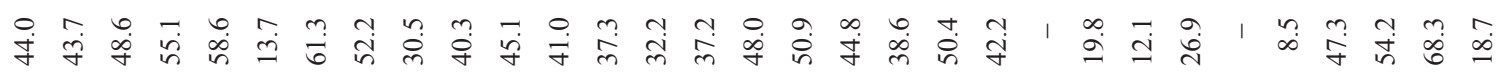
ஓं

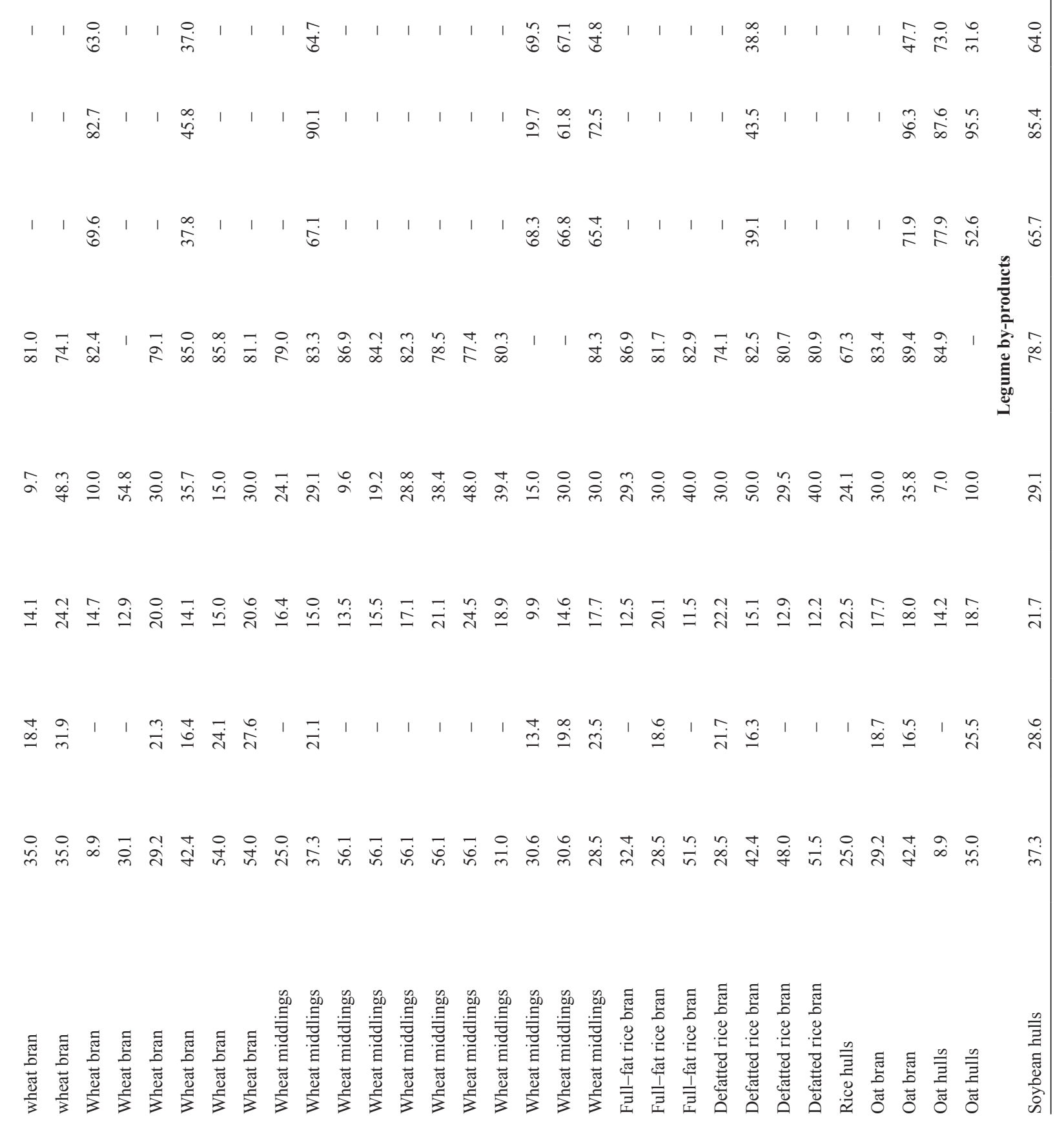




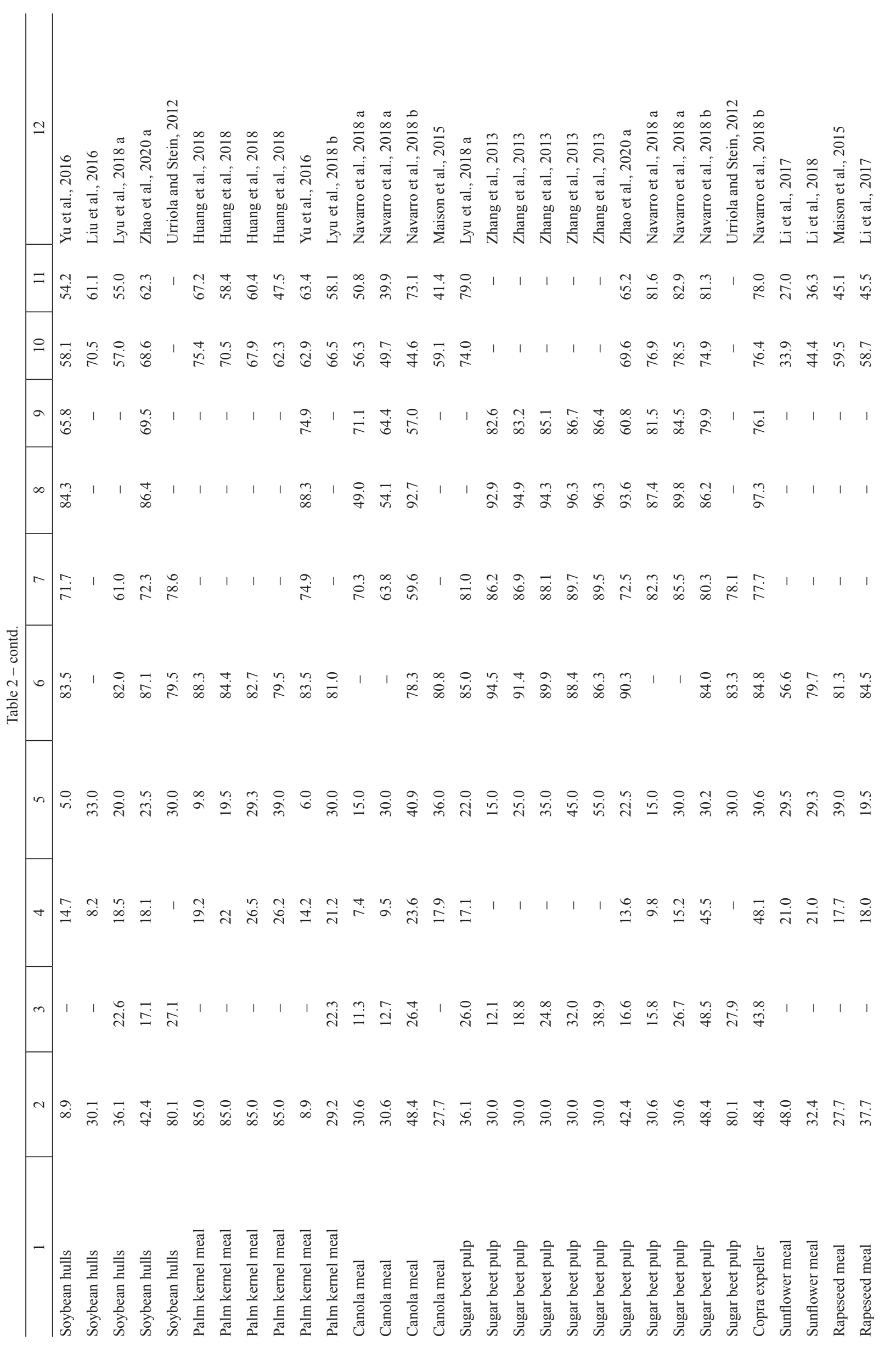




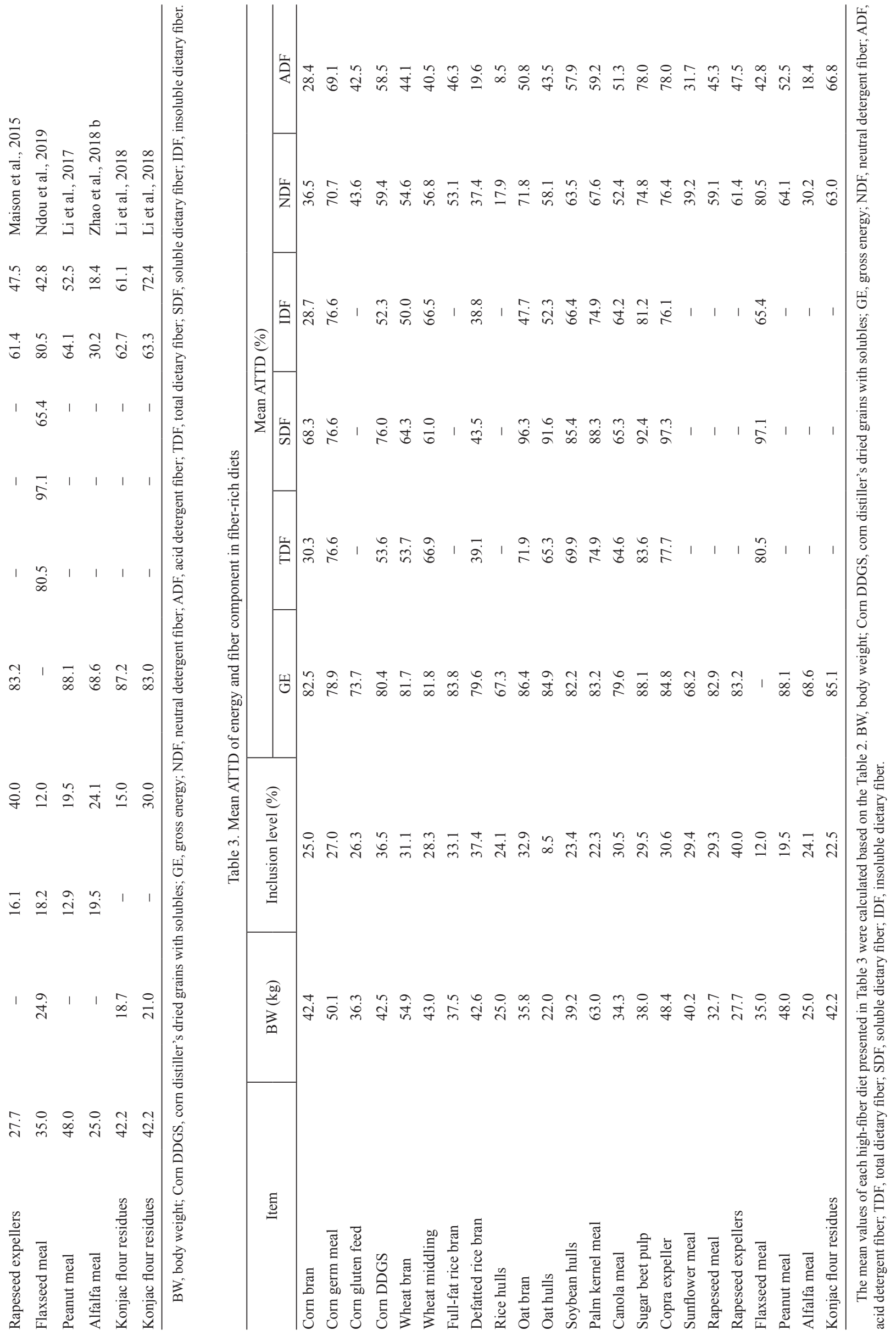


The ATTD of energy and fiber components in swine diets formulated with commonly-used fiber-rich ingredients are shown in Table 2. To compare energy and fiber digestibility among diets containing different high-fiber ingredients, mean ATTD of energy and fiber components were calculated and presented in Table 3. Zhao et al. (2018 b) reported that inclusion of $25 \%$ wheat middlings in diets had greater AID and ATTD of gross energy (GE) than diets containing $25 \%$ alfalfa meal or $25 \%$ rice hulls when fed to growing pigs, and the ATTD of neutral detergent fiber (NDF) and acid detergent fiber (ADF) in rice hulls diet was lower than those in wheat middlings or alfalfa meal diets. With equal TDF consumption, growing pigs fed pea hulls, pea inner fiber, or sugar beet pulp had greater ATTD of dry matter (DM) and non-starch polysaccharides (NSP) than those fed wheat bran or corn distiller's dried grains with solubles (corn DDGS) diets, but no differences in the AID of DM, NSP, and nitrogen were found among diets formulated with the other fibrous ingredients, except for sugar beet pulp (Jha and Leterme, 2012). Zhao et al. (2020 a) found that ATTD of TDF in different ingredients fed to growing pigs was $37.78 \%$ for wheat bran, $71.87 \%$ for oat bran, $72.54 \%$ for sugar beet pulp and $72.31 \%$ for soybean hulls. The poor digestibility of wheat bran can be ascribed to its high insoluble fiber content, which makes wheat bran less fermentable compared with sugar beet pulp and soybean hulls that containing highly fermentable pectin substances (KarrLilienthal et al., 2005). Jaworski and Stein (2017) reported that growing pigs fed a wheat middlings diet had greater apparent cecal digestibility of IDF compared with pigs fed diets containing corn DDGS or soybean hulls, and ATTD of TDF in wheat middlings diets was greater than that in corn DDGS or soybean hulls diets, indicating that fiber components in wheat middlings are more fermentable than those in corn DDGS and soybean hulls.

Effects of fiber source on nutrient digestibility and fiber fermentability in pigs depends on the physiochemical properties of various fiber-rich ingredients (Molist et al., 2014; Mpendulo et al., 2018). The different physiochemical characteristics of fiber-rich ingredients also affects SCFA production in the gut of pigs. Oat bran, rich in soluble dietary fiber in the form of $\beta$-glucan, can produce almost twice as much SCFA per gram of dietary fiber as wheat bran in pig's intestine (Zhao et al., 2019 a). Freire et al. (2000) investigated effects of adding wheat bran, sugar beet pulp, soybean hulls, or alfalfa meal at $20 \%$ of weaned pig diet on total SCFA concentration in the cecum, and reported that soybean hulls increased total SCFA concentration by $11.2 \%, 30.5 \%$, and $27.2 \%$ compared with wheat bran, sugar beet pulp, and alfalfa meal, respectively. Carneiro et al. (2008) compared effects of wheat bran and maize fiber addition to weaned pig diets, and they found no difference in total SCFA concentration in the small intestine of pigs, but greater acetate and lower butyrate production in cecum when maize fiber was used in diets compared with wheat bran. Zhao et al. (2018 a) reported that feeding pigs diets containing
$5 \%$ corn bran, wheat bran, or soybean hulls increased butyrate concentration in feces compared to a low-fiber control diet. Chen et al. (2014) reported that growingfinishing pigs fed $30 \%$ soybean hulls had greater acetate content in ileal digesta compared to those fed $30 \%$ wheat bran diet, and pigs fed 30\% wheat bran diet had greater butyrate content in the cecum than pigs fed $30 \%$ corn fiber, soybean fiber or pea fiber. Moreover, growing pigs fed pea hulls had greater butyrate and total SCFA concentrations compared to pigs fed wheat bran and corn DDGS diets, but no difference in total SCFA content was observed among wheat bran, pea hulls, pea inner fiber, sugar beet pulp and corn DDGS diets with similar levels of TDF (Jha and Leterme, 2012). Zhao et al. (2019 a) showed that growing pigs fed an oat bran diet (at 15\% TDF level) had greater lactate concentration in ileal digesta, and pigs fed soybean hulls and sugar beet pulp diets showed greater SCFA concentrations than those fed corn bran, rice bran, and wheat bran diets. Chemical and physical characteristics of intestinal digesta vary among fiber-rich ingredients at different gastrointestinal tract sites due to potential depolymerization or reduction in electrostatic repulsion among polysaccharides, resulting in varying nutrient digestibility (Capuano, 2017). Overall, these observations mentioned above support the conclusion that nutrient digestibility and fiber fermentation are influenced by dietary fiber sources due to their different physicochemical properties.

Some specific fiber components, such as cellulose, $\beta$-glucan, inulin, and resistant starch, extracted from plants have been supplied in diets to facilitate growth performance and gut health of pigs due to their benefits in promoting energy and nutrient digestibility. Gao et al. (2015) reported that growing pigs fed diets with 5\% carboxymethyl cellulose sodium showed greater AID of GE, crude protein (CP), ether extract (EE), DM, and carbohydrates compared to those fed diets with $5 \%$ inulin, but the ATTD and hindgut disappearance of GE, DM, $\mathrm{EE}$, and carbohydrates in a 5\% inulin diet were greater than those in 5\% carboxymethyl cellulose sodium diet. $\mathrm{Wu}$ et al. (2018) reported that weaned pigs fed a diet with $5 \% \beta$-glucan showed greater ATTD of DM and GE than those fed a diet with $5 \%$ cellulose because of the greater SDF concentration in $\beta$-glucan. In addition, pigs fed a $5 \%$ carboxymethylcellulose diet showed increased viscosity, decreased digesta passage rate, greater AID of GE, CP, and DM, and greater ATTD of GE and DM in comparison with those fed a diet with $5 \%$ cellulose or $\beta$-glucan (Hooda et al., 2011).

\section{Key factors affecting fiber digestibility in pigs} Dietary fiber level

As dietary fiber levels increase, enzymatic digestion and nutrient digestibility in pigs is increasingly impaired. For instance, ATTD of DM, organic matter (OM), GE, and CP decreased as dietary concentration of both konjac flour residues and ramie increased (Li et al., 2018). Huang et al. (2013) reported that ATTD of NDF and 
ADF in diets decreased linearly as inclusion level of wheat middlings increased from $9.6 \%$ to $48 \%$. Zhao et al. (2018 c) and Huang et al. (2018) also showed that ATTD of NDF and ADF in diets decreased as inclusion level of wheat bran increased from $15 \%$ to $45 \%$, or the inclusion level of palm kernel meal increased from $10 \%$ to $40 \%$. Wilfart et al. (2007) added $0 \%, 20 \%$, and $40 \%$ wheat bran to a wheat-barley-soybean meal diet and found that increased TDF level significantly decreased ATTD of DM, OM, CP, and GE, but ATTD of TDF was unaffected. In contrast, Zhang et al. (2013) reported that the ATTD of TDF, SDF, and IDF in sugar beet pulp increased linearly as the inclusion level of sugar beet pulp increased from $15 \%$ to $55 \%$. Additionally, Bindelle et al. (2009) reported that when growing pigs were fed cornsoybean meal diets supplemented with sugar beet pulp at levels of $0 \%, 10 \%, 20 \%$, and $30 \%$ with TDF levels increasing from $9.6 \%$ to $25.4 \%$, ATTD of DM, OM and CP linearly decreased but ATTD of NDF linearly increased. These divergent results may be caused as fiber inclusion levels increase, dietary fiber increasingly impairs enzymatic digestion in the upper gastrointestinal tract which simultaneously supports increased microbial activity and fiber fermentation in the hindgut of pigs (Noblet and Le Goff, 2001). Positive effects of increased fiber concentration on fiber digestibility were caused by greater quantity of substrates that flowed into the large intestine to be fermented. As a result, more SCFAs were produced and energy supplied by SCFA increased in the hindgut of pigs, even though nutrient digestibility and digestible energy in diets decreased as dietary fiber levels increased (Iyayi and Adeola, 2015). For example, high NSP concentrations resulted in an increased molar proportion of lactate in stomach and ileum, and an increased molar proportion of propionate and butyrate in the ileum (Högberg and Lindberg, 2004). Overall, considering the negative response of fiber level on nutrient digestibility in the upper gut and the positive response of fiber level on fermentation and SCFA production in the hindgut of pigs, it is necessary to determine the optimal inclusion level of dietary fiber in swine diets formulation.

To further demonstrate negative effects of dietary fiber level on energy digestibility, linear equations were developed to determine which fiber analysis methods of fiber components are best for studying relationships between dietary fiber levels and energy digestibility (Figure 2). The results showed that IDF $\left(R^{2}=0.77\right)$ is the best fiber component to predict energy digestibility of the diets compared with TDF $\left(R^{2}=0.69\right)$, SDF $\left(R^{2}<0.01\right)$, $\operatorname{NDF}\left(R^{2}=0.66\right)$ and $\operatorname{ADF}\left(R^{2}=0.57\right)$. The IDF, rather than NDF and ADF, should be used to precisely describe effects of fiber levels on dietary energy digestibility in pig production.
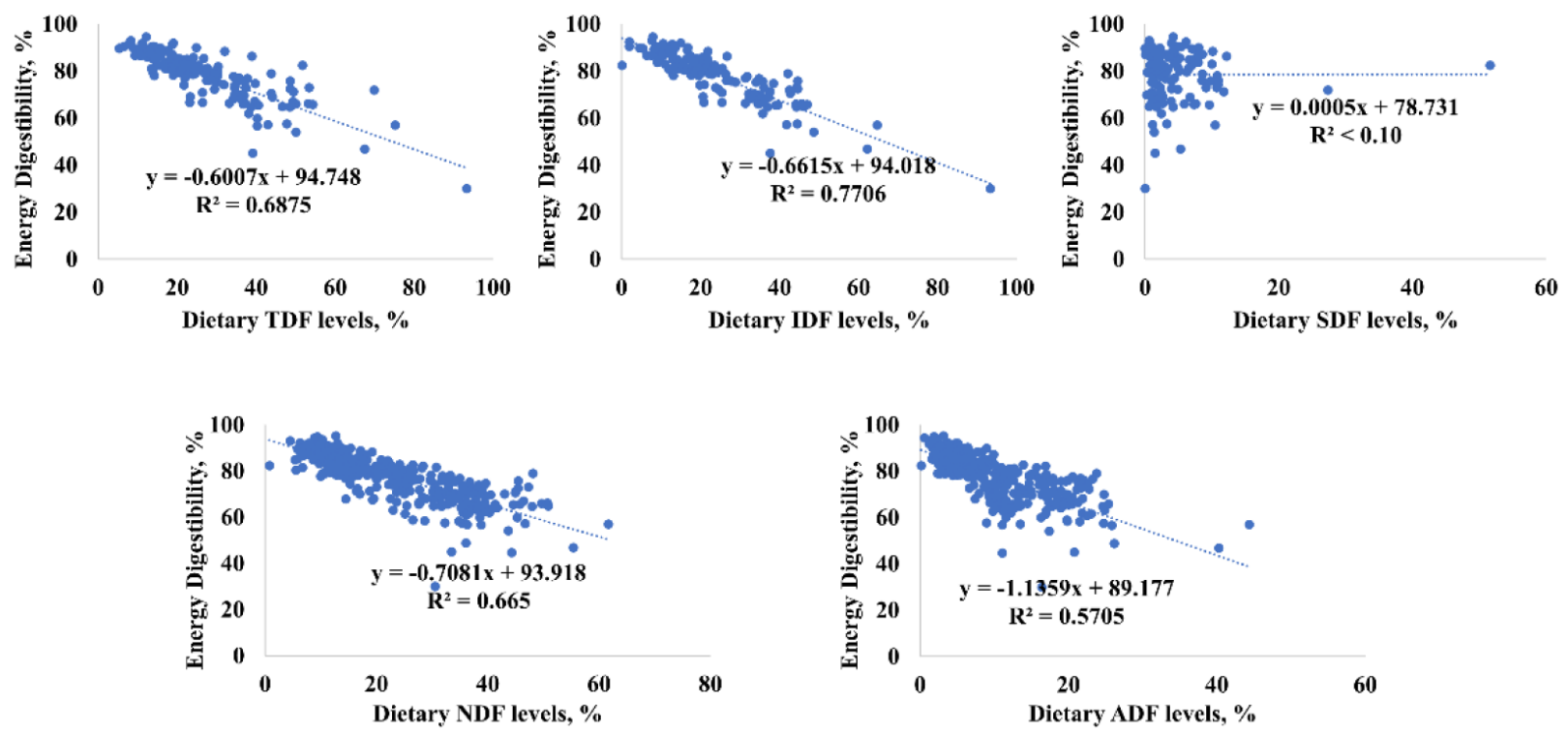

Data were separated by each dietary treatment and analyzed by analysis of variance using the PROC general linear model procedure of SAS (SAS 9.4 Institute, Cary, NC, USA) with pig as the experimental unit. The statistical models studied the effects of dietary TDF, IDF, SDF, NDF, and ADF levels on energy digestibility in growing pigs. The $R^{2}$ was used to identify which model best predicted energy digestibility. A larger $R^{2}$ represented a more accurate prediction equation. The equations developed using dietary NDF and ADF levels represented 118 dietary treatments in previously published studies (shown in Table 2), and equations developed using dietary TDF, SDF and IDF levels represented 51 dietary treatments from previously published studies. 


\section{Pig body weight and breed}

Compared with young pigs, adult pigs have a more developed and larger gastrointestinal tract, slower digesta transit time, higher cellulolytic activity and enhanced fermentability by resident microflora in the gut. Gestating sows had greater ATTD of energy in diets with 40\% full-fat rice bran or with $40 \%$ defatted rice bran compared with growing gilts regardless of feeding level (Casas and Stein, 2017). Pigs at 3 weeks post-weaning showed greater ATTD of all dietary components except for NDF compared to pigs just weaned (Ivarsson et al., 2011). Jørgensen et al. (2007) showed greater capacity of sows to digest fiber components and produce SCFA compared to young pigs, and demonstrated that sows could also degrade a larger proportion of dietary fiber in the small intestine than growing pigs. Sows have similar capacity to digesting soluble NSP when compared with growing pigs, even though sows can digest more insoluble NSP (Lindberg, 2014). Huang et al. (2015) reported that body weight of barrows (30 kg vs. $60 \mathrm{~kg}$ ) did not affect ATTD and AID of NDF and ADF, but increased ATTD and AID of carbohydrates as inclusion levels of wheat bran increased. Zhao et al. (2020 c) reported that barrows at 60 $\mathrm{kg}$ had greater ATTD of TDF, SDF, and IDF, and greater hindgut disappearance of IDF and cellulose compared to barrows at $25 \mathrm{~kg}$, but no differences in AID of most fiber components among barrows at different body weight stages, indicating the positive response of heavier growing pigs on dietary fiber fermentation mainly occurs in the large intestine. In addition, acetate, propionate, and total SCFA concentrations in ileal digesta and feces of barrows at $60 \mathrm{~kg}$ were greater than those of barrows at $25 \mathrm{~kg}$ (Zhao et al., $2020 \mathrm{c}$ ). Overall, growing pigs with higher body weight have greater capacity to digest dietary fiber components than lower body weight of pigs. Le Goff and Noblet (2001) stated that greater capacity of heavy pigs and adult sows to digest dietary fiber is due primarily to more advanced development of pig intestine, rather than enhanced intrinsic ability of gut microbiota to degrade dietary fiber.

Generally, pig breeds indigenous to China can utilize the high-fiber diets more efficiently than exotic crossbreds (Khieu et al., 2005; Len et al., 2007). Urriola and Stein (2012) reported that Meishan pigs had greater ATTD of DM, GE, CP, carbohydrates, and TDF than Yorkshire pigs when fed diets containing 29.1\% corn DDGS, but no differences in ATTD of nutrients were observed between Meishan and Yorkshire pigs when fed diets containing $29.1 \%$ soybean hulls or sugar beet pulp. Greater fiber digestibility in indigenous pig breeds could be mainly attributed to their larger cecum and colon compared with the exotic breeds, leading to longer retention time of digesta and increased dietary fiber fermentation by gut microbiota (Gao et al., 2015).

\section{Fiber-degrading enzyme}

As indicated by Zijlstra et al. (2010), enzyme supplementation can be an efficient approach to enhance utilization of nutrients in fiber-rich feedstuffs. Fiber degrading enzymes, such as cellulases, $\beta$-glucanases, pectinases, and xylanases, successfully improve digestibility of fiber fractions when the type of enzyme matches available substrates and enzymes are supplied at a proper dose. Högberg and Lindberg (2004) reported supplementation of $\beta$-glucanase and xylanase in diet increased the digestibility of total NSP in the cecum, but it had no effect on ATTD of total NSP in pigs fed diets with $9.6 \%$ or $18.3 \%$ NSP derived from cereals and wheat bran. A mixture of fiber-degrading enzymes improved digestibility of most NSP fractions and their constituent sugar residues in the duodenum and ileum of pigs fed diets with 53.7\% wheat bran or $33.0 \%$ soybean hulls, but did not affect the ATTD of fiber fractions (Liu et al., 2016). Therefore, an improvement of nutrient digestibility by dietary supplementation of fiber-degrading enzymes primarily occurs in the small intestine of pigs.

Jakobsen et al. (2007) reported addition of fiber-degrading enzymes, including a mixture of xylanase and $\beta$-glucanase or cellulase, improved both AID and ATTD of most fiber fractions in pigs fed a diet with $60 \%$ corn DDGS. A mixture of fiber-degrading enzymes improved digestibility of TDF and IDF in the large intestine when pigs were fed corn bran, sugar beet pulp or soybean hull diet, but did not influence fiber digestibility in the upper gut (Zhao et al., 2020 b). Lærke et al. (2015) reported there are interactive effects of fiber-degrading enzymes and chemical composition of diets on NSP digestibility in the small intestine of pigs. As a result, fiber-degraded enzymes should be chosen based on fiber ingredients in the diet to realize improvements in nutrient digestibility in the intestine.

\section{Adaptation period}

Nutrient digestibility and fiber fermentation are influenced by length of the adaptation period when pigs are fed high-fiber diets (Kil et al., 2013). Martinez-Puig et al. (2003) reported that the ATTD of OM and starch progressively increased in pigs fed $16 \%$ resistant starch when the adaptation period of diets increased from 23 days to 38 days. Similar results were also demonstrated in a longterm study with an adaptation period of 97 days (Martinez-Puig et al., 2007). Time-dependent changes in nutrient digestibility reflect the need of the gastrointestinal tract to adapt to dietary fiber supplementation. Previous studies showed that growing pigs are more easily adapted to sugar beet pulp diets compared with wheat bran diets (Roca-Canudas et al., 2007; Molist et al., 2009), which may be attributed to the greater SDF content in sugar beet pulp compared with wheat bran. Zhao et al. (2018 c) observed lower digestible energy content and ATTD of all chemical constituents when growing pigs were fed a wheat bran diet with a 7-day compared with a 14-day adaptation period. Huang et al. (2018) recommended a 21-day adaptation period for a diet containing 19.5\% palm kernel meal fed to growing pigs, and suggested longer adaptation period when inclusion levels of palm 
kernel meal increased. Fan et al. (2017) showed that ATTD of NDF was not different when comparing an adaptation period of 7 days and 26 days, but digestibility of other nutrients was affected in growing pigs. Considering the effects of high-fiber diets on feed intake, a 12-day adaptation period was recommended when determining net energy values of fiber-rich ingredients (Lyu et al., 2018 a). Overall, there is no consistent and specific conclusion concerning the optimal adaptation period for pigs consuming fibrous ingredients. Taking body weight and dietary fiber source into consideration, pigs with greater body weight may need shorter adaptation time especially when fed diets with high SDF and low IDF contents to achieve stable nutrient digestibility and fiber fermentability.

\section{Feed processing technology}

Reducing particle size of ingredients is beneficial in improving feed efficiency, nutrient digestibility, and fiber fermentation in swine diets (Ball et al., 2015; Rojas and Stein, 2015). Fine grinding increases surface area of diet particles, leading to greater access of digestive enzymes to nutrients (Hetland et al., 2004). Rojas et al. (2016) reported that pelleting or extrusion improved energy utilization in swine diets especially for those rich in fiber, but those processing technologies did not affect fiber digestibility in diets. Some recent studies showed that increased particle size of high-fiber ingredients is beneficial to gut health of pigs by modulating microbiota composition and SCFA production. For instance, Molist et al. (2012) reported that inclusion of coarsely ground wheat bran in diets shaped microbial community in the colon of pigs as compared with finely milled wheat bran, and addition of coarse wheat bran increased SCFA concentration. Although grinding would not change the chemical composition of feed, particle size can affect physical characteristics and digestible nutrient concentration of feed ingredients. Prebiotic effects of coarse fiber fractions on gut health of pigs might be explained by the change of physicochemical properties of digesta, such as increasing the water binding capacity, which is related to enhanced fiber fermentability and SCFA production in the hindgut of pigs (Anguita et al., 2006). Zhao et al. (2019 b) did not observe any differences in ATTD of nutrient and fiber components among pigs fed fibrous diets with different particle sizes, but coarse feed decreased the AID of GE, TDF, and IDF in diets and increased acetate concentration in feces. Overall, coarse particle size of fibrous feed decreases nutrient digestibility in small intestine, but increases fiber fermentation and SCFA production in the large intestine of pigs.

\section{Scientific issues related to quantifying SCFA pro- duction \\ Interestingly, many previous studies have reported negative values for fiber digestibility, especially in the small intestine of pigs (Ji et al., 2008; Jaworski and Stein, 2017). Negative fiber digestibility is physiologi-}

cal abnormal, indicating the presence of endogenous components from the gastrointestinal tract that would interfere with fiber analysis and decrease digestibility of fiber components. Bacteria and mucins, which may be the main sources for 'endogenous fiber losses', contain sugar residues that could be included in TDF during analysis (Miner-Williams et al., 2012). Average ileal and total tract endogenous losses of analyzed TDF were 25.25 and $42.87 \mathrm{~g} / \mathrm{kg}$ DM intake in growing pig, respectively (Cervantes-Pahm et al., 2014). Using a fiber-free diet, Montoya et al. (2016) found mucin was the main component of endogenous losses related to the SDF fraction in ileal digesta, and microbial cells were the main components of endogenous losses related to IDF fraction in ileal digesta and feces. Endogenous fiber losses in the pig intestine can be also fermented by gut microbiota to produce SCFA. Montoya et al. (2017) reported the SCFA produced from dietary fiber fermentation supplied by kiwifruit accounted for $30 \%$ of total SCFA produced in vitro using fecal microbiota of humans. With more dietary fiber consumed, both dietary fiber and non-dietary components entering into the hindgut increased, which in turn led to more SCFA production from both substrates. Although the non-dietary material is an important fraction of the digesta that enters into the hindgut of pigs, little information is available to quantify SCFA production from this source. Therefore, correction for endogenous loss of fiber components will improve the accuracy of SCFA produced by dietary fiber fermentation in pigs.

Most in vivo studies only determined SCFA produced by bacterial fermentation, while SCFA absorbed by epithelial cells of the gut is always neglected. The common method to quantify net absorption of SCFA is to employ a portal vein-catheterized pig model, in which blood samples are collected from portal vein and mesenteric artery to analyze SCFA concentrations (Bach Knudsen et al., 2000). Dietary fiber composition greatly affects net portal absorption of SCFA and concentrations of SCFA in portal vein and mesenteric artery of catheterized pigs fed cereal-based diets. An arabinoxylan-rich cereal-based diet stimulated proliferation of butyrate-producing microorganisms, butyrate production in the large intestine, and net portal absorption of butyrate to a larger extent than a resistant starch diet with equal amounts of TDF (Nielsen et al., 2014; Ingerslev et al., 2014). Therefore, absorption and net production of SCFA from gut microbiota to ferment different types of dietary fibers should be quantified to understand fermentability of dietary fibers and the possible pathways of SCFA metabolism in the gut of pigs.

\section{Conclusion}

There are large variations in fiber digestibility and SCFA concentration in small and large intestine of pigs when fed different fiber-rich ingredients. As inclusion level of dietary fiber increases or particle size of fibrous feed increases, nutrient digestibility in the small intestine of pigs decreases, but fiber fermentability and SCFA 
concentration in large intestine increase. Pigs with heavier body weight or consuming feed supplemented with fiber-degrading enzymes display increased fiber fermentation capacity and SCFA concentration in the intestine compared with lighter pigs. The IDF as a best variable to predict energy digestibility are recommended in application of pig production to achieve precise feeding. Further studies should be conducted to explore impacts of physical characteristics of fiber and endogenous fiber losses on dietary fiber fermentation and SCFA production in the intestine of pigs.

\section{Conflicts of Interest}

The authors declare no conflicts of interest.

\section{References}

Abelilla J.J., Stein H.H. (2019). Degradation of dietary fiber in the stomach, small intestine, and large intestine of growing pigs fed corn- or wheat-based diets without or with microbial xylanase. J. Anim. Sci., 97: 338-352.

Anguita M., Canibe N., Pérez J.F., Jensen B.B. (2006). Influence of the amount of dietary fibre on the available energy from hindgut fermentation in growing pigs: use of cannulated pigs and in vitro fermentation. J. Anim. Sci., 84: 2766-2778.

Bach Knudsen K.E., Canibe N., Jørgensen H. (2000). Quantification of the absorption of nutrients deriving from carbohydrate assimilation: model experiment with catheterised pigs fed on wheat and oat-based rolls. Brit. J. Nutr., 84: 449-458.

Bach Knudsen K.E., Hedemann M.S., Lærke H.N. (2001). The role of carbohydrates in intestinal health of pigs. Anim. Feed Sci. Technol., 83: 41-53.

Bach Knudsen K.E., Lærke H.N., Jørgensen H. (2013) Carbohydrates and carbohydrate utilization in swine. In: Sustainable swine nutrition, Chiba L.I. (ed.). John Wiley and Sons, Hoboken, USA, pp. 109-135.

Ball M.E.E., Magowan E., McCracken K.J., Beattie V.E., Bradford R., Thompson A., Gordon F.J. (2015). An investigation into the effect of dietary particle size and pelleting of diets for finishing pigs. Livest. Sci., 173: 48-54.

Bindelle J., Buldgen A., Delacollette M., Wavreille J., Agneessens R., Destain J.P., Leterme P. (2009). Influence of source and concentrations of dietary fiber on in vivo nitrogen excretion pathways in pigs as reflected by in vitro fermentation and nitrogen incorporation by fecal bacteria. J. Anim. Sci., 87: 583-593.

Capuano E. (2017). The behavior of dietary fiber in the gastrointestinal tract determines its physiological effect. Crit. Rev. Food Sci. Nutr., 57: 3543-3564.

Carneiro M.S.C., Lordelo M.M., Cunha L.F., Freire J.P.B. (2008). Effects of dietary fibre source and enzyme supplementation on faecal apparent digestibility, short chain fatty acid production and activity of bacterial enzymes in the gut of piglets. Anim. Feed Sci. Technol., 146: 124-136.

Casas G.A., Stein H.H. (2017). Gestating sows have greater digestibility of energy in full fat rice bran and defatted rice bran than growing gilts regardless of the level of feeding intake. J. Anim. Sci., 95: 3136-3142.

Casas G.A., Rodriguez D.A., Stein H.H. (2018). Nutrient composition and digestibility of energy and nutrients in wheat middlings and red dog fed to growing pigs. J. Anim. Sci., 96: 215-224.

Cervantes-Pahm S.K., Liu Y., Evans A., Stein H.H. (2014). Effect of novel fiber ingredients on ileal and total tract digestibility of energy and nutrients in semi-purified diets fed to growing pigs. J. Sci. Food Agric., 94: 1284-1290.

Chen H., Mao X.B., Che L.Q., Yu B., He J., Yu J., Han G.Q., Huang Z.Q., Zheng P., Chen D.W. (2014). Impact of fiber types on gut microbiota, gut environment and gut function in fattening pigs. Anim. Feed Sci. Technol., 195: 101-111.

Dégen L., Halas V., Tossenberger J., Szabó C., Babinszky L. (2009). The impact of dietary fiber and fat levels on total tract digestibility of energy and nutrients in growing pigs and its consequence for diet formulation. Acta Agric. Scand. A Anim. Sci., 59: 150-160.

Dikeman C.L., Fahey G.C. (2006). Viscosity as related to dietary fiber: a review. Crit. Rev. Food Sci. Nutr., 46: 649-663.

Fan Y., Guo P., Yang Y., Xia T., Liu L., Ma Y. (2017). Effects of particle size and adaptation duration on the digestible and metabolizable energy contents and digestibility of various chemical constituents in wheat for finishing pigs determined by the direct or indirect method. Asian-Australas. J. Anim. Sci., 30: 554-561.

Freire J.P.B., Guerreiro A.J.G., Cunha L.F., Aumaitre A. (2000). Effect of dietary fibre source on total tract digestibility, caecum volatile fatty acids and digestive transit time in the weaned piglet. Anim. Feed Sci. Technol., 87: 71-83.

Gao L., Chen L., Huang Q., Meng L., Zhong R., Liu C., Tang X., Zhang H. (2015). Effect of dietary fiber type on intestinal nutrient digestibility and hindgut fermentation of diets fed to finishing pigs. Livest. Sci., 174: 53-58.

Hetland H., Choct M., Svihus B. (2004). Role of insoluble non-starch polysaccharides in poultry nutrition. World. Poult. Sci. J., 60: 415-422.

Hooda S., Metzler-Zebeli B.U., Vasanthan T., Zijlstra R.T. (2011). Effects of viscosity and ferment ability of dietary fibre on nutrient digestibility and digesta characteristics in ileal-cannulated grower pigs. Brit. J. Nutr., 106: 664-674.

Högberg A., Lindberg J.E. (2004). Influence of cereal non-starch polysaccharides and enzyme supplementation on digestion site and gut environment in weaned piglets. Anim. Feed Sci. Technol., 116: $113-128$.

Huang Q., Piao X.S., Liu L., Li D.F. (2013). Effects of inclusion level on nutrient digestibility and energy content of wheat middlings and soya bean meal for growing pigs. Arch. Anim. Nutr., 67: 356-367.

Huang Q., Su Y.B., Li D.F., Liu L., Huang C.F., Zhu Z.P., Lai C.H. (2015). Effects of inclusion levels of wheat bran and body weight on ileal and fecal digestibility in growing pigs. Asian-Australas. J. Anim. Sci., 28: 847-854.

Huang C.F., Zhang S., Stein H.H., Zhao J., Li D.F., Lai C.H. (2018). Effect of inclusion level and adaptation duration on digestible energy and nutrient digestibility in palm kernel meal fed to growingfinishing pigs. Asian-Australas. J. Anim. Sci., 31: 395-402.

Ingerslev A.K., Theil P.K., Hedemann M.S., Lærke H.N., Bach Knudsen K.E. (2014). Resistant starch and arabinoxylan augment SCFA absorption, but affect postprandial glucose and insulin responses differently. Brit. J. Nutr., 111: 1564-1576.

Ivarsson E., Frankow-Lindberg B.E., Andersson K., Lindberg J.E. (2011). Growth performance, digestibility and faecal coliform bacteria in weaned piglets fed a cereal-based diet including either chicory (Cichorium intybus L) or ribwort (Plantago lanceolata L) forage. Animal, 5: 558-564.

Iyayi E.A., Adeola O. (2015). Quantification of short-chain fatty acids and energy production from hindgut fermentation in cannulated pigs fed graded levels of wheat bran. J. Anim. Sci., 93: 4781-4787.

Jakobsen G.V., Jensen B.B., Bach Knudsen K.B., Canibe N. (2007). Impact of fermentation and addition of non-starch polysaccharidedegrading enzymes on microbial population and on digestibility of dried distillers grains with solubles in pigs. Livest. Sci., 178: 216-227.

Jaworski N.W., Stein H.H. (2017). Disappearance of nutrients and energy in the stomach and small intestine, cecum, and colon of pigs fed corn-soybean meal diets containing distillers dried grains with solubles, wheat middlings, or soybean hulls. J. Anim. Sci., 95: 727-739.

Jaworski N.W., Liu D.W., Li D.F., Stein H.H. (2016). Wheat bran reduces concentrations of digestible, metabolizable, and net energy in diets fed to pigs, but energy values in wheat bran determined by the difference procedure are not different from values estimated from a linear regression procedure. J. Anim. Sci., 94: 3012-3021. 
Jha R., Leterme P. (2012). Feed ingredients differing in fermentable fibre and indigestible protein content affect fermentation metabolites and faecal nitrogen excretion in growing pigs. Animal, 6: 603-612.

Jha R., Rossnagel B., Pieper R., Van Kessel A., Leterme P. (2010). Barley and oat cultivars with diverse carbohydrate composition alter ileal and total tract nutrient digestibility and fermentation metabolites in weaned piglets. Animal, 4: 724-731.

Jha R., Bindelle J., Rossnagel B., Van Kessel A.G., Leterme P. (2011). In vitro evaluation of the fermentation characteristics of the carbohydrate fractions of hulless barley and other cereals in the gastrointestinal tract of pigs. Anim. Feed Sci. Technol., 163: 185-193.

Ji F., Casper D.P., Brown P.K., Spangler D.A., Haydon K.D., Pettigrew J.E. (2008). Effects of dietary supplementation of an enzyme blend on the ileal and fecal digestibility of nutrients in growing pigs. J. Anim. Sci., 86: 1533-1543.

Jørgensen H., Serena A., Hedemann M.S., Bach Knudsen K.E. (2007) The fermentative capacity of growing pigs and adult sows fed diets with contrasting type and level of dietary fibre. Livest. Sci. 109: 111-114.

Karr-Lilienthal L.K., Kadzere C.T., Grieshop C.M., Fahey Jr G.C. (2005). Chemical and nutritional properties of soybean carbohydrates as related to nonruminants: a review. Livest. Prod. Sci., 97: 1-12.

Kelkar S., Siddiq M., Harte J.B., Dolan K.D., Nyombaire G., Suniaga H. (2012). Use of low temperature extrusion for reducing phytohemagglutinin activity (PHA) and oligosaccharides in beans (Phaseolus vulgaris L) cv. Navy and Pinto. Food Chem., 133: 1636-1639.

Khieu B., Lindberg J.E., Ogle R.B. (2005). Effect of variety and preservation method of cassava leaves on diet digestibility by indigenous and improved pigs. Anim. Sci., 80: 319-324.

Kil D.Y., Kim B.G., Stein H.H. (2013). Invited review: Feed energy evaluation for growing pigs. Asian-Australas. J. Anim. Sci., 26: 1205-1217.

Koh A., De Vadder F., Kovatcheva-Datchary P., Backhed F. (2016) From dietary fiber to host physiology: short-chain fatty acids as key bacterial metabolites. Cell, 165: 1332-1345.

Lærke H.N., Arent S., Dalsgaard S., Bach Knudsen K.E. (2015). Effect of xylanases on ileal viscosity, intestinal fiber modification, and apparent ileal fiber and nutrient digestibility of rye and wheat in growing pigs. J. Anim. Sci., 93: 4323-4335.

Le Goff G., Noblet J. (2001) Comparative total tract digestibility of dietary energy and nutrients in growing pigs and adult sows. J. Anim. Sci., 79: 2418-2427.

Len N.T., Lindberg J.E., Ogle B. (2007). Digestibility and nitrogen retention of diets containing different levels of fibre in local (Mong Cai), F1 (Mong Cai $\times$ Yorkshire) and exotic (Landrace $\times$ Yorkshire) growing pigs in Vietnam. J. Anim. Physiol. Anim. Nutr. (Berl.), 91: 297-303.

Li E.K., Zhao J.B., Liu L., Zhang S. (2018). Digestible energy and metabolizable energy contents of konjac flour residues and ramie in growing pigs. Anim. Nutr., 4: 228-233.

Li Y.K., Li Z.C., Liu H., Noblet J., Liu L., Li D.F., Wang F.L., Lai C.H. (2018). Net energy content of rice bran, corn germ meal, corn gluten feed, peanut meal, and sunflower meal in growing pigs. AsianAustralas. J. Anim. Sci., 31: 1481-1490.

Li Z.C. (2017). Net energy prediction of plant protein ingredients to growing pigs. PhD thesis, China Agricultural University, China

Li Z.C., Li P., Liu D.W., Li D.F., Wang F.L., Su Y.B., Zhu Z.P., Piao X.S. (2017). Determination of the energy value of corn distillers dried grains with solubles containing different oil levels in growing pigs. J. Anim. Physiol. Anim. Nutr. (Berl.), 101: 339-348.

Lindberg J.E. (2014). Fiber effects in nutrition and gut health in pig. J. Anim. Sci., Biotech., 5: 15

Liu H., Wang J., He T., Becker S., Zhang G., Li D., Ma X. (2018) Butyrate: A double-edged sword for health? Adv. Nutr., 9: 21-29.

Liu Q., Zhang W.M., Zhang Z.J., Zhang Y.J., Zhang Y.W., Chen L., Zhang S. (2016). Effect of fiber source and enzyme addition on the apparent digestibility of nutrients and physicochemical properties of digesta in cannulated growing pigs. Anim. Feed Sci. Technol., 216: $262-272$.
Lyu Z.Q., Huang C.F., Li Y.K., Li P.L., Liu H., Chen Y.F., Li D.F., Lai C.H. (2018 a). Adaptation duration for net energy determination of high fiber diets in growing pigs. Anim. Feed Sci. Technol., 241: 15-26.

Lyu Z.Q., Huang B.B., Li Z.C., Wang Z.Y., Chen Y.F., Zhang S., Lai C.H. (2018 b). Net energy of oat bran, wheat bran, and palm kernel expellers fed to growing pigs using indirect calorimetry. Anim. Sci. J., 90: 98-107.

Lyu Z.Q., Li Y.K., Liu H., Li E.K., Li P.L., Zhang S., Wang F.L., Lai C.H. (2018 c). Net energy content of rice bran, defatted rice bran, corn gluten feed, and corn germ meal fed to growing pigs using indirect calorimetry. J. Anim. Sci., 96: 1977-1888.

Maison T., Liu Y., Stein H.H. (2015). Digestibility of energy and detergent fiber and digestible and metabolizable energy values in canola meal, 00-rapeseed meal, and 00-rapeseed expellers fed to growing pigs. J. Anim. Sci., 93: 652-660.

Martinez-Puig D., Pérez J.F., Castillo M., Andaluz A., Anguita M., Morales J., Gasa J. (2003). Consumption of raw potato starch increases colon length and fecal excretion of purine bases in growing pigs. J. Nutr., 133: 134-139.

Martinez-Puig D., Castillo M., Nofrariías M., Creus E., Pérez J.F. (2007). Long-term effects on the digestive tract of feeding large amounts of resistant starch: a study in pigs. J. Sci. Food Agric., 87: 1991-1999.

Miner-Williams W., Deglaire A., Benamouzig R., Fuller M.F., Tomé D., Moughan P.J., (2012). Endogenous proteins in terminal ileal digesta of adult subjects fed a casein-based diet. Am. J. Clin. Nutr., 96: 508-515.

Molist F., Gómez de Segura A., Gasa J., Hermes R.G., Manzanilla E.G., Anguita M., Pérez J.F. (2009). Effects of the insoluble and soluble dietary fibre on the physicochemical properties of digesta and microbial activity in early weaned piglets. Anim. Feed Sci. Technol., 149: 346-353.

Molist F., Ywazaki M., Gómez de Segura A., Hermes R.G., Gasa J., Pérez J.F. (2010). Administration of loperamide and addition of wheat bran to the diets of weaner pigs decrease the incidence of diarrhea and enhance their gut maturation. Brit. J. Nutr., 103: 879-885.

Molist F., Manzanilla E.G., Pérez J.F., Nyachoti C.M. (2012). Coarse, but not finely ground, dietary fibre increases intestinal Firmicutes:Bacteroidetes ratio and reduces diarrhoea induced by experimental infection in piglets. Brit. J. Nutr., 108: 9-15.

Molist F., van Oostruma M., Pérez J.F., Mateos G.G., Nyachoti C.M., van der Aar P.J., (2014). Relevance of functional properties of dietary fibre in diets for weanling pigs. Anim. Feed Sci. Technol., 189: 1-10.

Montoya C.A., Henare S.J., Rutherfurd S.M., Moughan P.J. (2016). Potential misinterpretation of the nutritional value of dietary fiber: correcting fiber digestibility values for nondietary gut-interfering material. Nutr. Rev., 74: 517-533.

Montoya C.A., Rutherfurd S.M., Moughan P.J. (2017). Ileal digesta nondietary substrates from cannulated pigs are major contributors to in vitro human hindgut short-chain fatty acid production. J. Nutr., 147: 264-271.

Mpendulo C.T., Chimonyo M., Ndou S.P., Bakare A.G. (2018). Fiber source and inclusion level affects characteristics of excreta from growing pigs. Asian-Australas. J. Anim. Sci., 31: 755-762.

Navarro D.M.D.L., Bruininx E.M.A.M., de Jong L., Stein H.H. (2018 a). The contribution of digestible and metabolizable energy from high-fiber dietary ingredients is not affected by inclusion rate in mixed diets fed to growing pigs. J. Anim. Sci., 96: 1860-1868.

Navarro D.M.D.L., Bruininx E.M.A.M., de Jong L., Stein H.H (2018 b). Effects of physicochemical characteristics of feed ingredients on the apparent total tract digestibility of energy, dry matter and nutrients by growing pigs. J. Anim. Sci., 96: 2265-2277.

Ndou S.P., Kiarie E., Ames N., Nyachoti C.M. (2019). Flaxseed meal and oat hulls supplementation: impact on dietary fiber digestibility, and flows of fatty acids and bile acids in growing pigs. J. Anim. Sci., 97: 291-301.

Nielsen T.S., Lærke H.N., Theil P.K., Sørensen J.F., Saarinen M., Forssten S., Bach Knudsen K.E. (2014). Diets high in resistant starch and arabinoxylan modulate digestion processes and SCFA 
pool size in the large intestine and faecal microbial composition in pigs. Brit. J. Nutr., 112: 1837-1848.

Roca-Canudas M., Anguita M., Nofrarías M., Majó N., Pérez de Rozas A.M., Martín-Orúe S.M., Pérez J.F., Pujols J., Segalés J., Badiola I. (2007). Effects of different types of dietary non-digestible carbohydrates on the physicochemical properties and microbiota of proximal colon digesta of growing pigs. Livest. Sci. 109: 85-88.

Rojas O.J., Stein H.H. (2015). Effects of reducing the particle size of corn grain on the concentration of digestible and metabolizable energy and on the digestibility of energy and nutrients in corn grain fed to growing pigs. Livest. Sci., 181: 187-193.

Rojas O.J., Vinyeta E., Stein H.H. (2016). Effects of pelleting, extrusion, or extrusion and pelleting on energy and nutrient digestibility in diets containing different levels of fiber and fed to growing pigs. J. Anim. Sci., 94: 1951-1960.

Sholly D.M., Jørgensen H., Sutton A.L., Richert B.T., Bach Knudsen K.E. (2011). Effect of fermentation of cereals on the degradation of polysaccharides and other macronutrients in the gastrointestinal tract of growing pigs. J. Anim. Sci., 89: 2096-2105.

Urriola P.E., Stein H.H. (2010). Effects of distillers dried grains with solubles on amino acid, energy, and fiber digestibility and on hindgut fermentation of dietary fiber in a corn-soybean meal diet fed to growing pigs. J. Anim. Sci., 88: 1454-1462.

Urriola P.E., Stein H.H. (2012). Comparative digestibility of energy and nutrients in fibrous feed ingredients fed to Meishan and Yorkshire pigs. J. Anim. Sci., 90: 802-812.

Urriola P.E., Shurson G.C., Stein H.H. (2010). Digestibility of dietary fiber in distillers coproducts fed to growing pigs. J. Anim. Sci., 88: 2373-2381.

Wang Z.Y., Chen Y.F., Ding J., Liu H., Lyu Z.Q., Dong W.X., Wang Z.J., Zhang S., Wang F.L. (2019). Net energy content of five fiberrich ingredients fed to pregnant sows. Anim. Sci. J., 90: 939-947.

Wilfart A., Montagne L., Simmins P.H., Van Milgen J., Noblet J. (2007). Sites of nutrient digestion in growing pigs: Effect of dietary fiber. J. Anim. Sci., 85: 976-983.

Williams B.A., Verstegen M.W.A., Tamminga S. (2001). Fermentation in the large intestine of single-stomached animals and its relationship to animal health. Nutr. Res. Rev., 14: 207-227.

Williams B.A., Mikkelsen D., Flanagan B.M., Gidley M.J. (2019). "Dietary fiber": moving beyond the "soluble/insoluble" classification for monogastric nutrition, with an emphasis on humans and pigs. J. Anim. Sci. Biotech., 10: 45.

Wu X., Chen D., Yu B., Luo Y., Zheng P., Mao X., Yu J., He J. (2018). Effect of different dietary non-starch fiber fractions on growth performance, nutrient digestibility, and intestinal development in weaned pigs. Nutrition, 51: 20-28.

Yu Z., Zhang S., Yang Q., Peng Q., Zhu J., Zeng X., Qiao S. (2016)
Effect of high fiber diets formulated with different fibrous ingredients on performance, nutrient digestibility and faecal microbiota of weaned piglets. Arch. Anim. Nutr., 70: 263-277.

Zhang W.J., Li D.F., Liu L., Zang J.J., Duan Q.W., Yang W.J., Zhang L.Y. (2013). The effects of dietary fiber level on nutrient digestibility in growing pigs. J. Anim. Sci. Biotech., 4: 17.

Zhang Z.Y., Liu Z.Y., Zhang S., Lai C.H., Ma D.L., Huang C.F. (2019) Effect of inclusion level of corn germ meal on the digestibility and metabolizable energy and evaluation of ileal AA digestibility of corn germ meal fed to growing pigs. J. Anim. Sci., 97: 768-778.

Zhao J.B., Liu P., Wu Y., Guo P., Liu L., Ma N., Levesque C., Chen Y., Zhao J.S., Zhang J., Ma X. (2018 a). Dietary fiber increases butyrate-producing bacteria and improves the growth performance of weaned piglets. J. Agric. Food Chem., 66: 7995-8004.

Zhao J.B., Wang Q., Liu L., Chen Y., Jin A., Liu G., Li K., Li D., Lai C. (2018 b). Comparative digestibility of nutrients and amino acids in high-fiber diets fed to crossbred barrows of Duroc boars crossed with Berkshire $\times$ Jiaxing and Landrace $\times$ Yorkshire. Asian-Australas. J. Anim. Sci., 31: 721-728.

Zhao J.B., Zhang S., Xie F., Li D., Huang C. (2018 c). Effects of inclusion level and adaptation period on nutrient digestibility and digestible energy of wheat bran in growing-finishing pigs. AsianAustralas. J. Anim. Sci., 31: 116-122.

Zhao J.B., Bai Y., Tao S., Zhang G., Wang J., Liu L., Zhang S. (2019 a). Fiber-rich foods affects gut bacterial community and short-chain fatty acids production in pig model. J. Funct. Foods., 57: 266-274.

Zhao J.B., Zhang G., Dong W.X., Zhang Y., Wang J.J., Liu L., Zhang S. (2019 b). Effects of dietary particle size and fiber source on nutrient digestibility and short chain fatty acid production in cannulated growing pigs. Anim. Feed Sci. Technol., 258: 114310.

Zhao J.B., Bai Y., Zhang G., Liu L., Lai C.H. (2020 a). Relationship between dietary fiber fermentation and volatile fatty acids' concentration in growing pigs. Animals, 10: 263.

Zhao J.B., Zhang G., Liu L., Wang J., Zhang S. (2020 b). Effects of fibre-degrading enzymes in combination with different sources on ileal and total tract nutrient digestibility and fermentation products in pigs. Arch. Anim. Nutr., 74: 309-324.

Zhao J.B., Liu X.Z., Zhang Y., Liu L., Wang W.W., Zhang S. (2020 c). Effects of body weight and fiber sources on fiber digestibility and short chain fatty acid concentration in growing pigs. AsianAustralas. J. Anim. Sci., 33: 1975-1984.

Zijlstra R.T., Owusu-Asiedu A., Simmins P.H. (2010). Future of NSPdegrading enzymes to improve nutrient utilization of co-products and gut health in pigs. Livest. Sci., 134: 255-257.

Received: 9 III 2021

Accepted: 15 VI 2021 